only way to deal with the condition with any chance of success, although the results of second operations for the celief of obstruction of the bowels within a few days of an abdominal section are extremely discouraging. The case I have related would seem to have been a favourable one for sach an attempt owing to the existence of only one small point of adhesion. I had, however, never seen symptoms due to obstruction beginning so early and progressing so iapidly. Hence I wavered in my opinion as to the cause of the patient's condition, and unfortunately did not reopen the abdomen.

CASE 3.- On March 25th, 1887, I performed ovariotomy on a young woman twenty-one years of age, who suffered from a large ovarian tumour, with consequent emaciation and debility. She was otherwise healthy, but of decidedly strumous constitution. The tumour grew from the left orary, and no difficulty was met with in removing it. The right ovary was healthy. On the evening of the day following the operation the temperature rose to $103^{\circ}$ in the axilla, the pulse was 120 , and the patient complained of severe pain in the left side of the pelvis. Ice was applied to the head till the following morning, when the temperature had come down to $99^{\circ}$. The patient was now free from pain, and her condition seemed in every way satisfactory, except that the wound did not heal well supersially. The bowels were moved by enema on the sixth morning, and every second or third day afterwards by enema or by laxative medicine. With the exception of a temporzry rise to $102^{\circ}$ on the eleventh evening the temperature was not above $99.4^{\circ}$ in the axilla till the fifteenth day after the operation, when it again rose. I then found a slight thickening of the tissues to the left of the aterus The temperature after this was from $100^{\circ}$ to $102^{\circ}$ wery evening. On the twenty-third day I detected a hardmess of the tissues just above the inner end of the left Poupart's ligament. On internal examination a large mass was discovered filling the left side of the pelvis. There was evidently a suppurating cellulitis pushing up the peritoneum and barrowing forwards. The abdomen was poulticed, and three days later some pus burst through the lower end of the wound. The discharge was very free for sume days, and then became scanty. The general condition now greatly improved. There was no pain, and the upper part of the wound healed rapidly. On the thirty-third day the patient again complained of severe pain, this time in the right side of the pelvis. An examination showed that a large very tender swelling had developed on that side also, while much indurated tissue remained on the left side, the uterus being firmly fixed between. The temperature now cose high every evening, frequently above $104^{\circ}$ in the axilla. The patient had a severe rigor on the thirtyseventh day. There was at this time still a sinus leading three inches into the left side of the pelvis, but there was never any evidence of a second escape of pus. After ten days of severe hectic fever a slight general improvement began. Convalescence was very slow and repeatedly interrupted by febrile exacerbations. The wound did not heal till three months after the operation, and it was a month and a half later before the uterus became at all movable. Menstruation was in abeyance from five weeks before the operation till Aug. 17th, exactly six months. The periods were quite regular before and after that time, but were painful for a few months after their return. The patient has since continued quite well.

(To be concluded.)

\section{MORE THAN TWO HUNDRED CASES OF INFLUENZA TREATED WITH LARGE} DOSES OF SALICIN.

BY E. B. TURNER, F.R.C.S. ENG., L.R.C.P. LoND.

LAST year Dr. Maclagan published in THE LANCET the results of several cases of influenza which he had treated by the administration of large doses of salicin with excellent results. I have now treated a series of more than two jundred cases, both last year and this, with this remedy, and have found it extremely satisfactory. In the early days of the epidemic of 1890 I contracted the disease myself, and at once took large doses (twenty grains) of salicin every hour, with the result that my temperature, which was $105^{\circ}$ at 5 P.M., was normal at 8 A.M., and all pain and discomfort had ceased; so that I was able to go out and do my work as usual, and, though weak and rather depressed for a few days, soon completely recovered. Since them I have treated every case I have met with on the same plan, and with the greatest success. I have not seen a single complication, not one case of bronchitis or pneumonia, and the only sequelæ brought to my notice have been three in numberviz, a slight attack of gout, a return of neuritis (of a gouty origin), from which the patient had recovered just before the onset of the influenza, and two or three attacks of spasmodic asthma in a man who had been subject to that ailment all his life, and which attacks were not complicated by any bronchial catarrh. The cases have all run a similar course, and convalescence has been practically established in twenty-four hours. I append notes of a typical case, with the treatment.

A. B_, male, age forty-two, on May 9th, 1891, awoke with sharp pains in back and limbs, intense headache, and general malaise. At 10.30 A.M. face flushed, conjunctivæ injected, tongue coated, complaining of pains as above. Temperature $104.4^{\circ}$; pulse 120 . To take twenty grains of salicin in powder every hour. To have plenty of soup, milk, eggs and milk, and three or four glasses of champagne during the day. 7.30 P.M.: Pains nearly gone. Temperature $100 \cdot 2^{\circ}$; pulse 96 ; free perspiration. To continue the powders through the night every three hours. May 10 th (10.45 A.M.): "Feels quite well ;" no pain; tongue nearly clean; temperature $98^{\circ}$; pulse 76 . To take one powder every four hours till evening, and then to discontinne them. To eat any light food fancied, with a glass of champagne at lunch and at dinner. To get up in the afternoon.-11th: Patient practically well; allowed downstairs; convalescence perfect and uninterrupted.

In the following case inability to retain the salicin at first somewhat retarded the usual speedy cure, but as soon as the sickness ceased the patient rapidly improved. On May 18th C. D-, female aged eighteen, while driving after lunch suddenly exhibited typical influenza symptoms. 4.30 P.M.: Acute pain in head, back, and limbs; face flushed and conjunctivæ injected. Temperature $103 \cdot 6^{\circ}$; pulse 120 . Constant and severe vomiting of green bilious matter. To take twenty grains of salicin every hour, and small quantities of soup, milk, champagne, and soda water with ice.-May 19th (10.30 A.Mr.): Much the same; owing to the constant vomiting but little of the salicin has been retained; some tenderness and pain in epigastric region. Temperature $102 \cdot 3^{\circ}$; pulse 120 . To take at once a draught containing twenty-five minims of tincture of opium and three minims of diluted hydrocyanic acid (B.P.) in water, and then to continue the previous treatment. 7.30 P.M. : Sickness much less. Salicin and food fairly well retained. Pains less. Temperature $99 \cdot 4^{\circ}$; pulse 96 . To continue the salicin every two hours. - 20th (10.30 A.M.): Practically convalescent. Temperature $98.3^{\circ}$; pulse 72 . This was the only case in which the temperature remained elevated and the pain continued for more than twenty-four hours.

The salicin treatment appears to me to diminish the infectiousness of the disease. I have had many cases, one or sometimes two in a house, but in no case have I found the malady spread until a whole household was down with it at the same time. The greatest number of cases seen in any one establishment is six, and these occurred three at a time at an interval of ten days from two distinct infections. It seems to me that salicin, by cutting the course of the disease short in the individual, renders him much less infectious to his fellows than if the fever had been allowed to run its usual course unchecked. I have found that the sooner the remedy can be administered after the first onset of the symptoms, the sooner do those symptoms abate, and if a case can be treated at once after the first shiver a normal temperature and freedom from pain are ensured in about six hours. The same treatment has proved beneficial to patients of all ages, children of three years and old persons of seventy have recovered equally quickly, the dose being of course graduated according to the age of the recipient. Some of the cases treated were of a sthenic character, the pulse and fever running high. In others the symptoms were distinctly asthenic, the temperature being about $101^{\circ}$ and the pulse weak, Under such circumstances stimulants were freely given, but in either case the sheet anchor was salicin, and in erery instance it acted like a charm. In the whole series of cases there has not been any complication, such as bronchitis or pneumonia, calculated to cause ten minutes' anxiety, 
and not a single nurse has been necessary for the treatment of any of the patients. On recovery the subsequent depression was much less and of much shorter duration than in similar cases which I had treated with quinine and salines before trying the experiment of the large and frequent doses of salicin on myself. Had my experience of the effects of this drug been limited to two or three cases, I might have been inclined to put the good results down to accident, or to a run of mild attacks, which would have quickly recovered under any treatment; but the actual number of cases thus managed is 215 , and they are continuous in series, with an unbroken record of success. This seems a sufficient number to eliminate accident, and it is hardly probable that every case which it has fallen to my lot to see during the whole of this epidemic and the greater part of last year's visitation was of so slight a character that it would have spontaneously got well in twenty-four hours, without sequel or complication. Granting that infuenza is an infectious fever, possibly septic, attacking mainly the nerve centres, I think that the known therapeutics of salicin may to some extent explain its apparently specific action in this disease. If it be given in such doses as twenty grains an hour for ten or twelve con. secutive hours, the blood must become thoroughly saturated with it, and, therefore (owing to its antiseptic properties), a very bad medium for the multiplication of germs or microbes of any sort. Salicin also bas a marked effect on the whole nervous system. May it not, therefore, so to say, attack the disease in its headquarters, while its well-known antifebrile action reduces the temperature and alleviates the symptoms? In conclusion, whatever cause may be assigned for the results I have set forth above, I can recommend this drug freely administered as a safe, sure, and successful method of treatment for a very troublesome ailment.

Sussex-gardens, $w$.

\section{GANGRENE OF LUNG FOLLOWING ACUTE LOBAR PNEUMONIA IN A BOY; RECOVERY.}

BY H. WALTER SYERS, M.D.,

PHYSICIAN TO OUT-PATIENTS, GREAT NORTHERN CENTRAL HOSPITAL.

THE termination of acute lobar pneumonia in gangrene of the lung is admittedly a rare occurrence. Still more rare is it in the case of a previously healthy child, and very few cases are on record in which it has ended in recovery. Gangrene of the lung is referred to by Dr. Walshe as "one of the very rarest terminations of pneumonia." I Drs. Sturges and Coupland say, speaking on the same subject: " The rarity with which gangrene occurs as a sequel of acute pneumonia is well illustrated by the returns furnished to the Collective Investigation Committee. Out of the 1065 cases so returned, gangrene resulted only in two, both being old subjects and one a drunkard.". There can, I think, be no doubt that the following case is one of gangrene occurring very early in the course of lobar pneumonia, and rapidly leading to the formation of a cavity which was recognised by the usual physical signs of such a con. dition. The question of empyema was of course entertained at an early period of the case, but the evidence of such collection in the pleural cavity was never strong, and this explanation of the symptoms was soon put on one side. Why in a healthy boy of eleven an acute pneumonia should result in gangrene is a question more easily asked than answered. There was no evidence whattver of septic infection, and the only probable explanation appears to be that the intensity of the inflammation at the outset $w$ as such as to lead to rapid death of what was probably only a small portion of lung. The very satisfactory recovery of the patient is also a remakable circumstance. Dr. Walshe says : " "The prognosis of gangrene of the lung cannot be held to be absolutely fatal," and he regards onetwelfth of the number of cases as altogether too high an estimate of the proportion of recoveries. For the early notes of the case I am indebted to Dr. Cribb of Highbury.

R. C-, aged eleven, schoolboy; admitted to the Great Northern Central Hospital on Sept. 10th, 1890. 'The patient's previous health had been in all respects good. The family history was unimportant. On Aug. 30th, being in his usual good health, he went to the Zoological Gardens, where he lost his cap and came home bareheaded. Shortly after his return he had a distinct rigor. The next day (3lst) he complained of headache and nausea. On Sept. 1st he went to school, but was sent home by the teacher as he was too unwell to attend. His face was flushed, he had lost appetite, and had slight cough. On Sept. 6th he was worse, delirious, and complained of pain on the right side of the chest. He was first seen by Dr. Cribb on Sept. 7 th. He was then very short of breath, and complained of severe pain in the right axillary region. Temperature was $102^{\circ}$. The right chest was dull on percussion over the lower lobe, and as far as the angle of the scapula, the breathing in the same region being tubular. During the night he raised himself in bed suddenly, and began coughing and retching, throwing up a quantity of extremely offensive pus, estimated by the mother as being enough to fill a breakfast cup in the total amount, for he continued to expectorate small quantities of similar matter during the night and the next morning. On admission on Sept. 10th he had a distressed expression, with obvious movement of the alæ nasi. The pulse was 100 ; respiration 35 . He com. plained of pain in the right side of the chest on deep inspiration. The tongue was moist; no sordes. There was slight cough, with fetid expectoration. There were physical signs of consolidation of the right lower lobe, and much pleural friction was audible in the right lateral region. The temperature on admission was $101 \cdot 8^{\circ}$. During the next few days his temperature varied between $101^{\circ}$ and $102^{\circ}$, and on the 14th was normal. During this time he continued to expectorate large quantities of excessively fetid purulent matter, the fetor being that characteristic of gangrene The breath also had the same odour, which was greatly intensified by coughing. At this time signs of cavity began to present themselves at the apex of the right lower lobe-cavernous breath-sounds, gurgling, pectoriloquy. At the same time the remainder of the lung showed dnlness on percussion and crepitation. On the 16 th the temperature was $101^{\circ}$. He was now in a very exhausted condition, greatly emaciated, and sweated freely at night. The sputa of gangrenous odour continued to be expectorated in large quantity. Microscopical examination of the expectoration showed the presence of pus-corpuseles and elastic fibres. The temperature varied between $100^{\circ}$ and $102^{\circ}$ until Sept. 22nd, when it fell to normal, but speedily rose again. On the $29 \mathrm{ch}$ the temperature rose from $98^{\circ}$ to $103 \cdot 4^{\circ}$, but shortly afterwards fell. After this date a marked improvement occurred. On Oct. 6 th the fetor was still present, but less marked, and the expectoration was not so abundant. At the same time the signs of cavity became gradually less obvious over the apex of the right lower lobe. By Oct. 10th the temperature had fallen to normal, and over the right back the only abnormal phy. sical signs were dulness on percussion and some crepitation. Bronchial breathing was limited to the apex of the iight lower lobe. The improvement was now rapid and great. The expectoration entirely ceased, and he rapidly gained in weight. A few days later there were no moist sounds any. where, except at the apex of the right lower lobe. Examination on Oct. 27th showed defective resonance over the right lower lobe, but with neither bronchial breathing nor crepitation. He was now up and about, had a good appetite, and had gained flesh, being indeed well. A few days later he left the hospital for a convalescent home. Devonshire-street, $\mathrm{W}$.

SIMPLE PERFORATING ULCER OF SIGMOID PRODUCING A UNIQUE PELVIC SWELLING, AND COEXISTING $G$ WITH ALVEOLAR CANCER OF THE BODY OF THE UTERUS.

BY JAMES OLIVER, M.D., F.R.S.EDIx.

B. B-, aged fifty-seven and single, came under my care on March 14th, 1891. She began to menstruate at the age of fourteen, and the discharge, which had always been free, had usually lasted seven days. Menstruation ceased ten years ago. For eighteen months the patient has conplained of a more or less constant discharge from the ragina. For six months it was merely tinged with blood 